\title{
A Novel Neutral-Point Potential Balance Strategy for Three-Level NPC Back-to-Back Converter Based on the Neutral-Point Current Injection Model
}

\author{
Yingjie Wang, Haiyuan Liu, Wenchao Wang, and Kangan Wang \\ School of Information and Electrical Engineering, China University of Mining and Technology, Xuzhou 221116, China \\ Correspondence should be addressed to Yingjie Wang; wyj971@126.com
}

Received 15 October 2014; Revised 2 February 2015; Accepted 2 February 2015

Academic Editor: Kim M. Liew

Copyright (c) 2015 Yingjie Wang et al. This is an open access article distributed under the Creative Commons Attribution License, which permits unrestricted use, distribution, and reproduction in any medium, provided the original work is properly cited.

The neutral-point (NP) potential balance control in three-level neutral-point-clamped (NPC) back-to-back converter is a research nodus. Its current strategies are the same as the strategies of a single three-level NPC converter. But the strategies do not give full play to its advantages that the neutral-point current can only flow through the connected midlines in both sides of the converter but does not flow through the DC-bus capacitors. In this paper, firstly the NP potential model based on the NP current injected is proposed. It overcomes numerous variable constraints and mutual coupling in the conventional model based on the zero-sequence voltage injected. And then on this basis, three NP-potential balance control algorithms, unilateral control, bilateral independent control, and bilateral coordinated control, are proposed according to difference requirements. All of these algorithms use the midlines rather than the DC-bus capacitors to flow the NP current as much as possible. Their control abilities are further quantitatively analyzed and compared. Finally, simulation results verify the validity and effectiveness of these algorithms.

\section{Introduction}

The three-level neutral-point-clamped (NPC) back-to-back converter is composed of two three-level NPC topologies. The converter has the advantages of high power factor, two-way flow of energy, good control performance, and less pollution to the power grid. So in some medium-voltage and largecapacity applications, the converter has been a research focus in recent years [1-3].

Due to the inconsistent energy transmission to the upper and lower DC-bus capacitors in the three-level NPC topology, the voltages on two sets of capacitors might change so as to make NP potential unbalanced and fluctuated $[4,5]$. This will eventually result in uneven voltage on its power devices and low-order current harmonics. The power device can be damaged by too high voltage. The current harmonics can cause torque ripple of electric machinery and lower efficiency. The frequent fluctuations of NP potential also reduce the lifetime of the capacitors. So the NP potential balance control in three-level NPC topology is widely studied.
The NP potential balance strategy in three-level NPC back-to-back converter commonly uses the strategy of the single three-level NPC topology [6-8] and works in the rectifier side or inverter side. Based on the space vector modulation, there are two kinds of the strategies: precise control [9] and hysteresis control [10]. It is relatively simple for the hysteresis control only to select the appropriate large or small switching vectors, but NP potential has to fluctuate within a certain range. In precise control, NP potential can remain stable in the controllable range, namely, low modulation ratios and high power factors. But it is more complicated to calculate the precise work time of the switching vectors. In order to reduce the complexity, A P (proportional) or PI (proportional integral) controller in [11] is used to control NP potential. But these controllers cause the limitations of the response speed and accuracy. In order to control NP potential in all modulation ratios and power factors, a virtual-vector control strategy is proposed in [12]. But the strategy is at the expense of increasing the switching frequency of power devices. Besides these control strategies, 


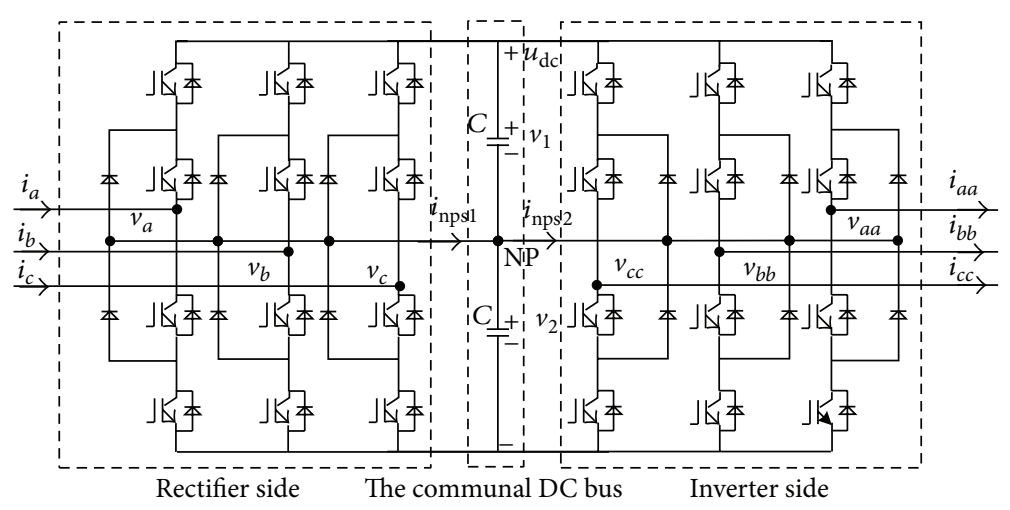

FIGURE 1: The topology of the three-level NPC back-to-back converter.

many strategies based on the carrier modulation are also proposed. In [13], the NP potential fluctuation is inhibited by injecting zero-sequence voltage. But this strategy does not take into consideration numerous variable constraints and mutual coupling between zero-sequence voltage and the modulation voltage, which weakens its control ability. In $[14,15]$, the strategy is further improved by predicting the appropriate zero-sequence voltage.

NP current is required to be zero at any time for NP potential stabilization in these above strategies used in the single three-level NPC topology. However, the inflow and outflow of NP currents are just required to be equal rather than being zero in two parts of the three-level NPC backto-back converter, because two midlines are connected at NP. So these strategies cannot fully play the advantage of the converter. Moreover, the NP current in the rectifier side or inverter side where NP potential is not controlled could generate adverse effect to the NP potential [16-18].

This paper firstly improves NP potential control model based on zero-sequence voltage injected and further builds the NP potential model based on the NP current injected in order to avoid the numerous variable constraints and mutual coupling in Section 2. The NP-current injection range in a single switching cycle is obtained from the new model. According to different control needs, three algorithms, unilateral control, bilateral independent control, and bilateral coordination control, which are suitable for the characteristic of the converter, are, respectively, proposed in Section 3. Section 4 clarifies their control abilities and applicable occasions through comparative analysis of these three algorithms. Finally, the authors demonstrate the correctness and validity of the proposed algorithms by the simulation experiments in Section 5.

\section{The NP Potential Model Based on the NP Current Injected}

The topology of the three-level NPC back-to-back converter is shown in Figure 1. It is made up of two three-level NPC topologies connected to the communal DC bus. Rectifier side and inverter side, respectively, connect to the grid and threephase loads. If the inflow $i_{\text {nps } 1}$ and outflow $i_{\text {nps } 2}$ of NP currents are not equal, the NP potential would fluctuate. Because the converter is symmetrical, this paper only analyzes the control mechanism of NP potential by the rectifier side.

In the three-phase three-wire system, the actual voltages of rectifier side $\left[v_{x}(x=a, b, c)\right]$ can contain zero-sequence voltage, and their expressions are defined as

$$
v_{x}=v_{x 1}+v_{0}
$$

where $\left[v_{x 1}(x=a, b, c)\right]$ are the reference voltages obtained from the upper control system. $v_{0}$ is the zero-sequence voltage.

Before the analysis, several assumptions should be made.

(1) In a switching cycle, the state of a power device is allowed to change only for once.

(2) The upper and the lower sets of capacitors in the communal DC bus have the same capacitance $[C(F)]$.

(3) Compared with the fundamental frequency, the modulation frequency is so high that the phase currents $i_{x}(x=a, b, c)$ might be considered as a constant in a switching cycle.

(4) $u_{\mathrm{dc}} / 2\left(u_{\mathrm{dc}}\right.$ is the DC-bus voltage) is selected as the basic value. So (1) is rewritten as follows:

$$
v_{x}^{*}=v_{x 1}^{*}+v_{0}^{*},
$$

where $v_{x}^{*}, v_{x 1}^{*}$, and $v_{0}^{*}$ are, respectively, per unit values of the actual voltages, the reference voltages, and the zero-sequence voltage. Their absolute values must be less than 1 .

As shown in Figure 2(a), if NP is treated as the reference point, the switch state can be set as $\left[S_{x}=-1,0,1(x=\right.$ $a, b, c)]$. Only if the switch state is zero, the phase currents should flow through the NP. The phase current in the $n$th switching cycle is considered as a constant $i_{x}(n)$ in Figure 2(b). When the time of the nonzero switching state in the $n$th switching cycle is $\left|v_{x}^{*}(n)\right| T\left(v_{x}^{*}(n) T\right.$ or $\left.-v_{x}^{*}(n) T\right)$, the percentage of the nonzero switching state is equal to $\left|v_{x}^{*}(n)\right|$. So the current $i_{\text {nps- } x}(n)$ of each phase that is injected 


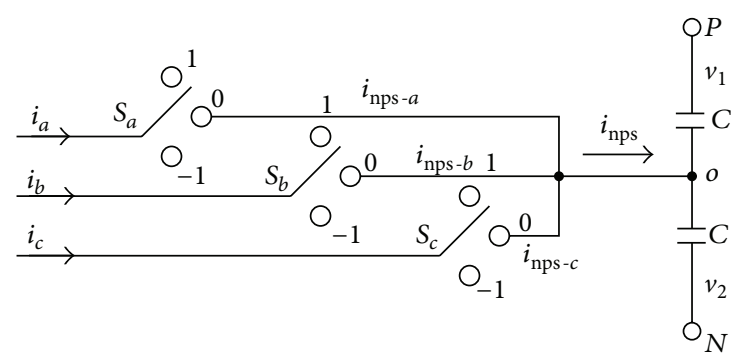

(a)

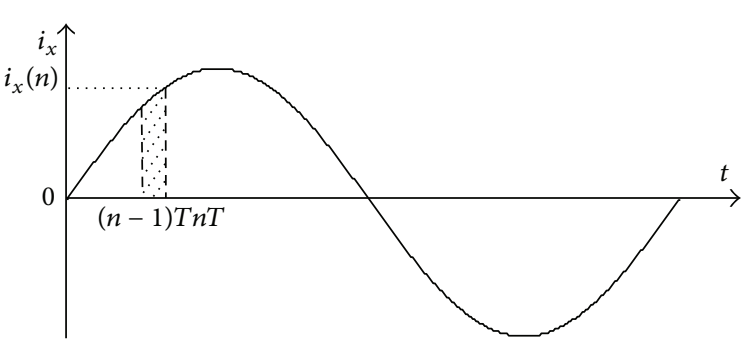

(b)
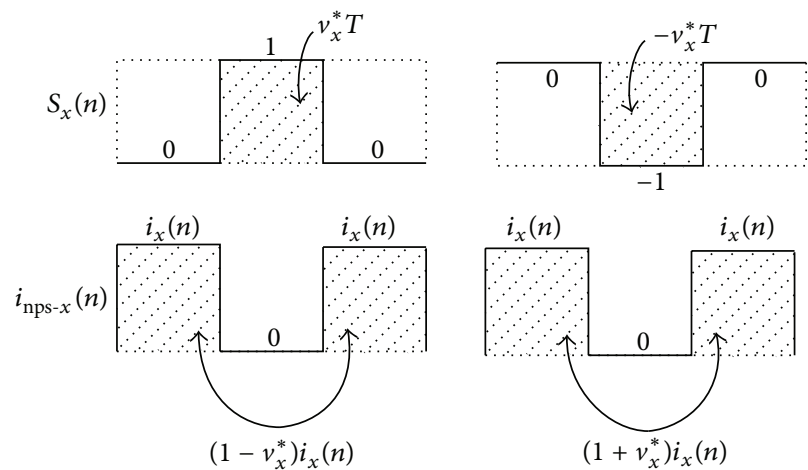

(c)

Figure 2: The NP-current injection schematics.

into the NP in the $n$th switching cycle is $\left(1-\left|v_{x}^{*}(n)\right|\right) i_{x}(n)$ $\left(\left(1-v_{x}^{*}(n)\right) i_{x}(n)\right.$ or $\left.\left(1+v_{x}^{*}(n)\right) i_{x}(n)\right)$, as shown in Figure 2(c). Finally, the NP current can be obtained as

$$
\begin{aligned}
i_{\text {nps }} & =\sum_{x=a, b, c} i_{\text {nps }-x}=\sum_{x=a, b, c}\left(1-\left|v_{x}^{*}\right|\right) \cdot i_{x} \\
& =-\sum_{x=a, b, c} \operatorname{sgn}\left(v_{x}^{*}\right) \cdot v_{x}^{*} \cdot i_{x},
\end{aligned}
$$

where the sign function is defined as

$$
\begin{array}{r}
\operatorname{sgn}\left(v_{x}^{*}\right)= \begin{cases}1 & v_{x}^{*} \geq 0 \\
-1 & v_{x}^{*}<0\end{cases} \\
(x=a, b, c) .
\end{array}
$$

Equation (3) shows that $v_{x}^{*}$ determines the NP current. As $v_{x 1}^{*}$ from the upper control system has been already identified, $v_{0}^{*}$ is only a free variable to change the NP current. Inserting (2) in (3), the zero-sequence voltage is obtained as

$$
v_{0}^{*}=-\frac{\sum_{x=a, b, c} \operatorname{sgn}\left(v_{x}^{*}\right) \cdot v_{x 1}^{*} \cdot i_{x}-i_{\text {nps }}}{\sum_{x=a, b, c} \operatorname{sgn}\left(v_{x}^{*}\right) \cdot i_{x}} .
$$

Equation (5) shows that the sign of $v_{x}^{*}$ must be firstly gotten for the zero-sequence voltage. But (2) shows the zerosequence voltage must be firstly gotten for the sign of $v_{x}^{*}$. So there is a coupling between them. Suppose the signs of $v_{x}^{*}(x=a, b, c)$ are the same, the denominator of (5) could be given by

$$
\sum_{x=a, b, c} \operatorname{sgn}\left(v_{x}^{*}\right) \cdot i_{x}=\operatorname{sgn}\left(v_{x}^{*}\right) \sum_{x=a, b, c} i_{x}=0 .
$$

Obviously, the zero-sequence voltage is no answer at this time. So there must be at least one opposite sign in $v_{x}^{*}$ in order to ensure an answer. That is to say, there are two situations: two positive and one negative or two negative and one positive. The different-sign one in $v_{x}^{*}$ is named $v_{r}^{*}$. Its corresponding grid current and reference voltage are named as $i_{r}$ and $v_{r 1}^{*}$, respectively. $v_{r}^{*}$ must be the maximum or minimum. Taking them into (5), $v_{0}^{*}$ can be obtained as

$$
v_{0}^{*}=-v_{r 1}^{*}+\frac{p}{2 i_{r}}-\frac{i_{\text {nps }}}{2 \operatorname{sgn}\left(v_{r}^{*}\right) \cdot i_{r}},
$$

where $p=\sum_{x=a, b, c} v_{x 1}^{*} \cdot i_{x}$.

Let the reference voltages from the upper control system be sorted by size as $\left[\begin{array}{lll}v_{\max 1}^{*} & v_{\operatorname{mid} 1}^{*} & v_{\min 1}^{*}\end{array}\right]$, and their corresponding currents are set as $\left[\begin{array}{lll}i_{\max } & i_{\text {mid }} & i_{\text {min }}\end{array}\right]$. Obviously, $v_{r 1}^{*}$ must be the maximum voltage $v_{\max 1}^{*}$ or the minimum voltage $v_{\min 1}^{*}$, and its corresponding phase current is $i_{\max }$ or $i_{\min }$. When the sign of $v_{r}^{*}$ is positive, $v_{r 1}^{*}$ must be $v_{\max 1}^{*}$. When the sign of $v_{r}^{*}$ is negative, $v_{r 1}^{*}$ must be $v_{\min 1}^{*}$. Thus, the zerosequence voltage has two possible solutions:

$$
v_{0}=\left\{\begin{array}{l}
-v_{\max 1}^{*}+\frac{p}{2 i_{\max }}-\frac{i_{\mathrm{nps}}}{2 i_{\max }} \\
-v_{\min 1}^{*}+\frac{p}{2 i_{\min }}+\frac{i_{\mathrm{nps}}}{2 i_{\min }} .
\end{array}\right.
$$




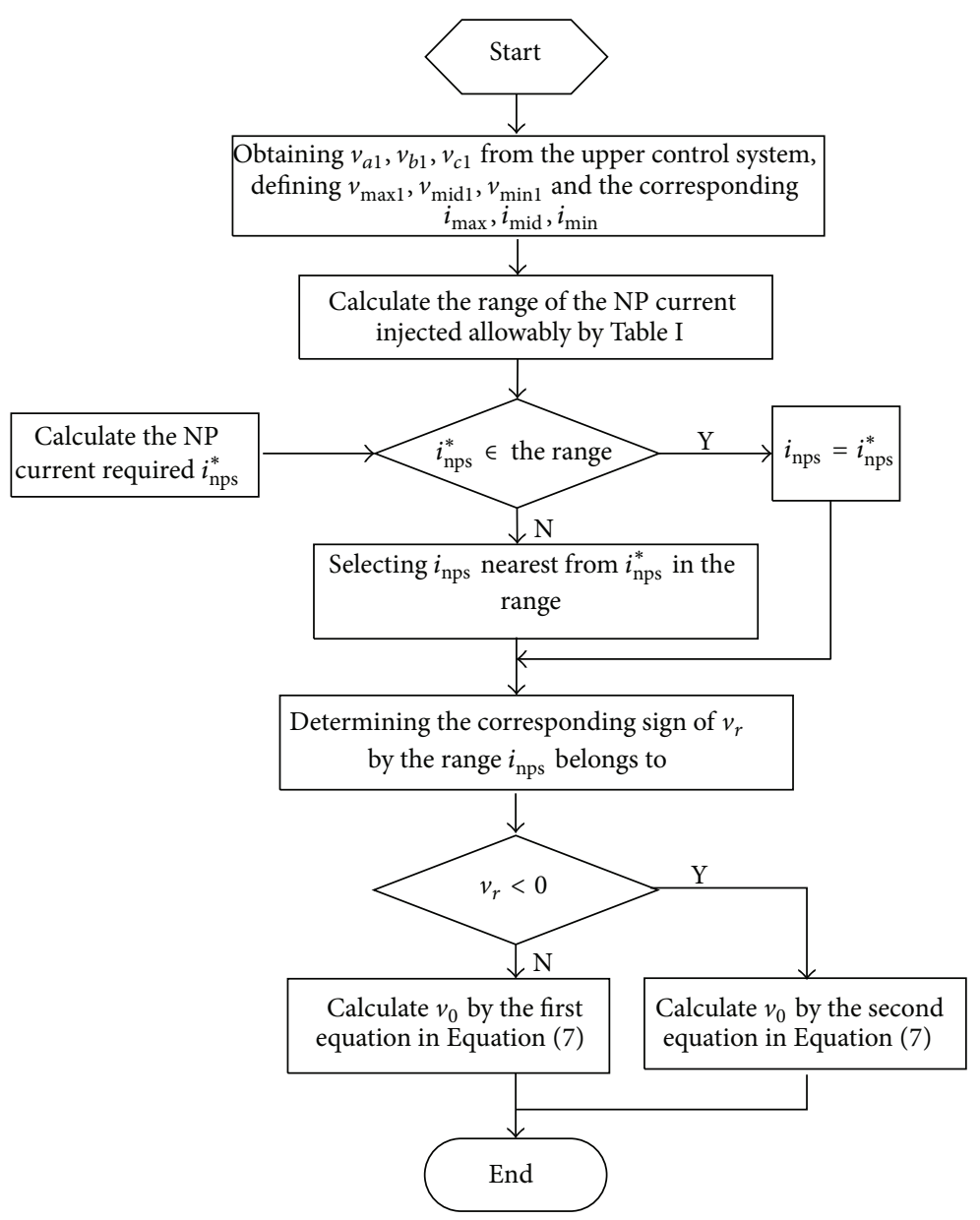

FIGURE 3: The calculation flowchart of the zero-sequence voltage.

It can be seen that the coupling no longer exists in (8). However, when $\omega=2 k \pi / 3$ or $\omega=(2 k+1) \pi / 3(k=$ $0, \pm 1, \pm 2, \pm 3, \ldots), v_{r 1}^{*}$ is only one equal to the maximum or the minimum, so the possible answer of the zero-sequence voltage is only one or none. As the following algorithms meet the two cases, this paper will not discuss it.

Since $v_{x}^{*}$ must be less than 1 , the zero-sequence voltages obtained from (8) might not satisfy these constraints. If the constraints are not satisfied, an optimal zero-sequence voltage needs to be reselected. Taking into consideration the sign of $v_{r}^{*}$, the two sets of constraints are listed as follows:

$$
\begin{aligned}
& 0 \leq v_{\max 1}^{*}+v_{0} \leq 1 \\
& -1 \leq v_{\operatorname{mid} 1}^{*}+v_{0}<0 \\
& -1 \leq v_{\min 1}^{*}+v_{0}<0 \\
& 0 \leq v_{\max 1}^{*}+v_{0} \leq 1 \\
& 0 \leq v_{\operatorname{mid} 1}^{*}+v_{0} \leq 1 \\
& -1 \leq v_{\min 1}^{*}+v_{0}<0 .
\end{aligned}
$$

TABLE 1: The range of the NP current injected allowably.

\begin{tabular}{lcc}
\hline & $i_{\max } \geq 0, v_{r}^{*} \geq 0$ & $i_{\max }<0, v_{r}^{*} \geq 0$ \\
\hline$i_{\min } \geq 0, v_{r}^{*}<0$ & {$\left[i_{x}, i_{y}\right],\left[i_{u}, i_{v}\right]$} & {$\left[i_{y}, i_{x}\right],\left[i_{u}, i_{v}\right]$} \\
\hline$i_{\min }<0, v_{r}^{*}<0$ & {$\left[i_{x}, i_{y}\right],\left[i_{v}, i_{u}\right]$} & {$\left[i_{y}, i_{x}\right],\left[i_{v}, i_{u}\right]$} \\
\hline where $i_{x}=p-2 i_{\max } \min \left(1, v_{\max 1}^{*}-v_{\text {mid } 1}^{*}\right), i_{y}=p-2 i_{\max } \max \left(0, v_{\max 1}^{*}-\right.$ \\
$\left.v_{\text {min } 1}^{*}-1\right) ;$ \\
$i_{u}=-p-2 i_{\min } \min \left(1, v_{\text {mid } 1}^{*}-v_{\text {min } 1}^{*}\right), i_{v}=-p-2 i_{\min } \max \left(0, v_{\max 1}^{*}-v_{\min 1}^{*}-\right.$
\end{tabular}

The zero-sequence voltages in (8) are substituted separately into (9). After simplification, the range of the NP current injected allowably is obtained, as shown in Table 1.

If $i_{\text {max }} \geq 0, v_{r}^{*} \geq 0$, the NP-current injection range is $\left[i_{x}, i_{y}\right]$. If $i_{\max }<0, v_{r}^{*} \geq 0$, the NP-current injection range is $\left[i_{y}, i_{x}\right]$. If $i_{\min } \geq 0, v_{r}^{*}<0$, the NP-current injection range is $\left[i_{u}, i_{v}\right]$. If $i_{\text {min }}<0, v_{r}^{*}<0$, the NP-current injection range is $\left[i_{v}, i_{u}\right]$. Since the sign of $v_{r}^{*}$ can be positive or negative, the range of the NP current injected allowably has two choices in a switching cycle. Determine whether the NP current required is in the NP-current injection range. If yes, the NP current required is substituted into the appropriate equation 


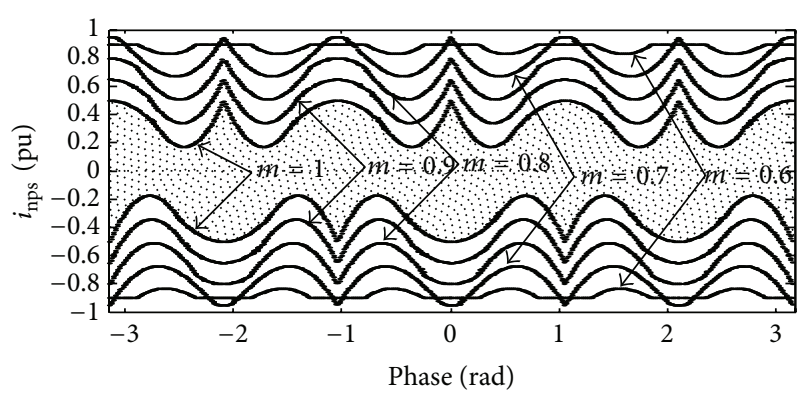

(a)

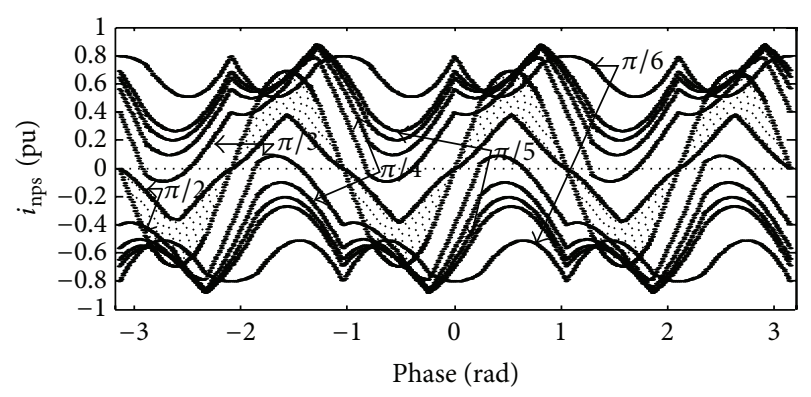

(b)

FIgURE 4: The NP-current injection range with various modulation ratios and phase differences.

in (8) according to the sign of $v_{r}^{*}$ for obtaining the zerosequence voltage. If not, the NP current that is in this range and has the minimum distance to the NP current required, namely, the boundary value, is substituted for obtaining the optimal zero-sequence voltage. Thus, this method can make the NP-potential fluctuation minimum. The NP potential model based on the NP current injected is composed of (8) and Table 1. The calculation flowchart of the zero-sequence voltage based on this model is shown in Figure 3.

Suppose the reference voltages obtained from the upper system and grid currents all are the ideal positive-sequence waves. Using Table 1, the NP-current injection range with the various modulation ratio and phase difference can be obtained, as shown in Figure 4. The basic value of the NP current is the grid-current amplitude in Figure 4. Figure 4(a) is the NP-current injection ranges when phase difference between the reference voltage and the grid current is zero and the modulation ratio is different. Figure 4(b) shows the NPcurrent injection ranges when phase difference is different and the modulation ratio is 0.8 . Some conclusions can be drawn from Figure 4, as follows.

(1) Two NP-current injection ranges can be combined practically, which can be also obtained from Table 1 .

(2) If modulation ratio and phase difference are smaller, the range of the NP current being equal to zero will be greater and the NP-potential fluctuation will be smaller. The range is the maximum when phase difference is zero. Conversely, high modulation ratio and large phase difference would cause small range and deteriorate the controllability of the NP potential.
(3) Grid-current amplitude also has a great impact on the NP potential fluctuation. The NP-current injection range is a multiple of grid-current amplitude. If the NP current injected allowably cannot be equal to zero, the NP-potential fluctuation amplitude would also be a multiple of grid-current amplitude.

(4) No matter what modulation ratio and phase difference are, the NP-current range is cyclical and the cycle is $2 \pi / 3$.

\section{NP-Potential Balanced Control Algorithms of the Three-Level NPC Back-to-Back Converter}

According to the NP potential model based on the NP current injected, the NP-current injection ranges in the rectifier side and inverter side can be, respectively, calculated by the reference voltages and phase currents of both sides. And then an optimal inflow and an optimal outflow current at the NP are selected from the two ranges according to different requirements. At last, optimal zero-sequence voltages injected in both sides are obtained from (8). This paper presents three algorithms as follows.

3.1. Unilateral Control. Zero-sequence voltage in one side of the three-level NPC back-to-back converter, generally in the inverter side, may need to meet some certain specific requirements, such as improving modulation ratio, reducing switching frequency, or suppressing common mode voltage. So the NP potential is only controlled in the other side. In this case, the NP current required is calculated by

$$
i_{\mathrm{nps} 1}^{*}=\frac{C\left(v_{1}-v_{2}\right)}{T}+i_{\mathrm{nps} 2}
$$

where $i_{\text {nps } 2}$ is the NP current in the inverter side which can be calculated by (3), $v_{1}$ and $v_{2}$ are, respectively, the upper and the lower capacitor voltages in the communal DC bus, and $T$ is a switching cycle.

Determine whether $i_{\mathrm{nps} 1}^{*}$ is in the NP-current injection range in the rectifier side. If so, $i_{\mathrm{nps} 1}^{*}$ is substituted into the appropriate equation in (8) according to the sign of $v_{r}^{*}$ for obtaining the zero-sequence voltage. If not, the NP current that is in this range and has the minimum distance to $i_{\mathrm{nps} 1}^{*}$, namely, the boundary value, is substituted for obtaining the optimal zero-sequence voltage. Thus, it makes the minimum NP-potential fluctuation. The unilateral control flow is shown in Figure 5.

3.2. Bilateral Independent Control. If the zero-sequence voltage of both sides can be used to control the NP potential, the NP current injected in each side may be half of the NP current required, which is shown in

$$
i_{\mathrm{nps} 1}^{*}=-i_{\mathrm{nps} 2}^{*}=\frac{C\left(v_{1}-v_{2}\right)}{2 T} .
$$

Determine whether $i_{\mathrm{nps} 1}^{*}, i_{\mathrm{nps} 2}^{*}$ are, respectively, in the NP-current injection ranges in the rectifier side and inverter 


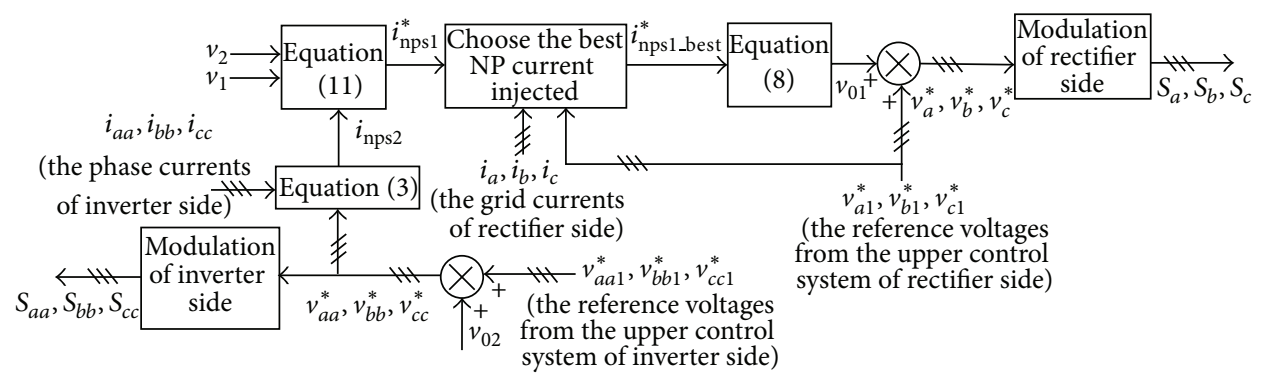

FIgURE 5: The block diagram of unilateral control.

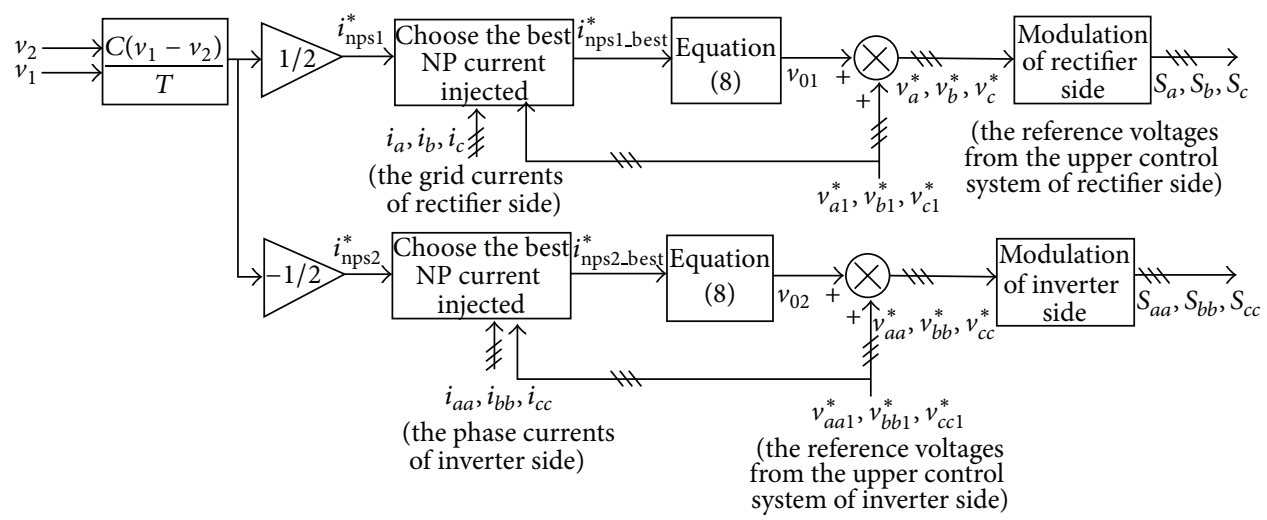

FIGURE 6: The block diagram of bilateral independent control.

side. If yes, $i_{\text {nps1 }}^{*}, i_{\text {nps2 }}^{*}$ are, respectively, substituted into the appropriate equation in (8) according to the sign of $v_{r}^{*}$ for obtaining the zero-sequence voltage. If not, the NP currents, which have the minimum distances to $i_{\text {nps1 }}^{*}, i_{\text {nps2 }}^{*}$ in the NPcurrent injection ranges in the rectifier side and inverter side, are, respectively, substituted to obtain the optimal zerosequence voltage. The bilateral independent control flow is shown in Figure 6.

3.3. Bilateral Coordinate Control. In fact, NP-potential balance in the three-level NPC back-to-back converter only needs to meet the premise that the difference between the inflow and the outflow currents at the NP is equal to the NP current required. Taking advantage of the premise to achieve NP-potential balance, it would undoubtedly expand the control range and achieve better control effect. In this case, the NP currents required in both sides are calculated by

$$
i_{\mathrm{nps} 1}^{*}-i_{\mathrm{nps} 2}^{*}=\frac{C\left(v_{1}-v_{2}\right)}{T} .
$$

Similarly, the NP-current injection ranges in rectifier side and inverter side may be calculated by Table 1 . Assume that these two ranges are $\left[i_{m r}, i_{x r}\right]$ and $\left[i_{m i}, i_{x i}\right]$, respectively. Three possible cases between the NP current required and the NPcurrent injection range of the three-level NPC back-to-back converter are shown in Figure 7. The abscissa represents the NP current in the rectifier side. The ordinate represents the NP current in the inverter side. The shaded area is the NPcurrent injection range of the three-level NPC back-to-back

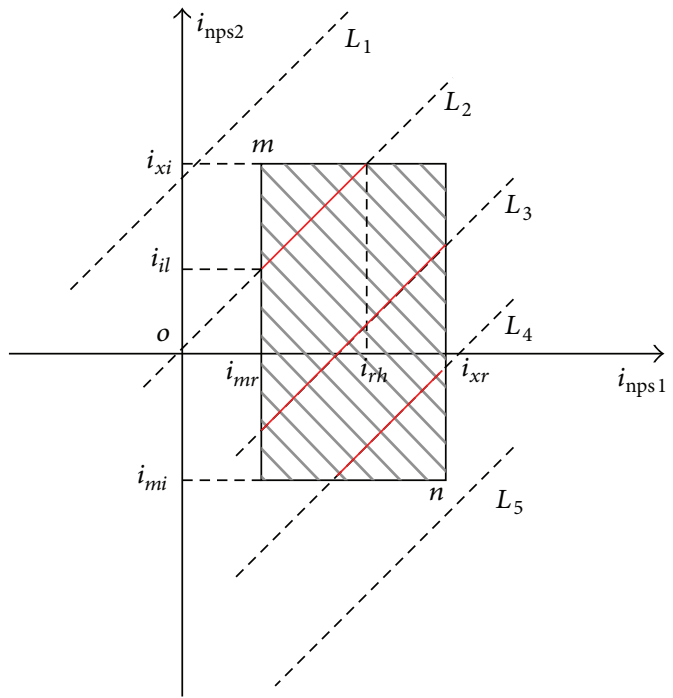

FIGURE 7: Three possible cases between the NP current required and the NP-current injection range of the three-level NPC back-to-back converter.

converter, and the dotted lines represent the NP currents required in both sides that can meet (12). Then according to different positions between the dotted line and the shaded area, there will be three possible cases. The line $L_{1}$ does not cross the shaded area, but $m\left(i_{r m}, i_{i x}\right)$ is the nearest point from line $L_{1}$. So $m\left(i_{r m}, i_{i x}\right)$ are, respectively, taken to calculate 


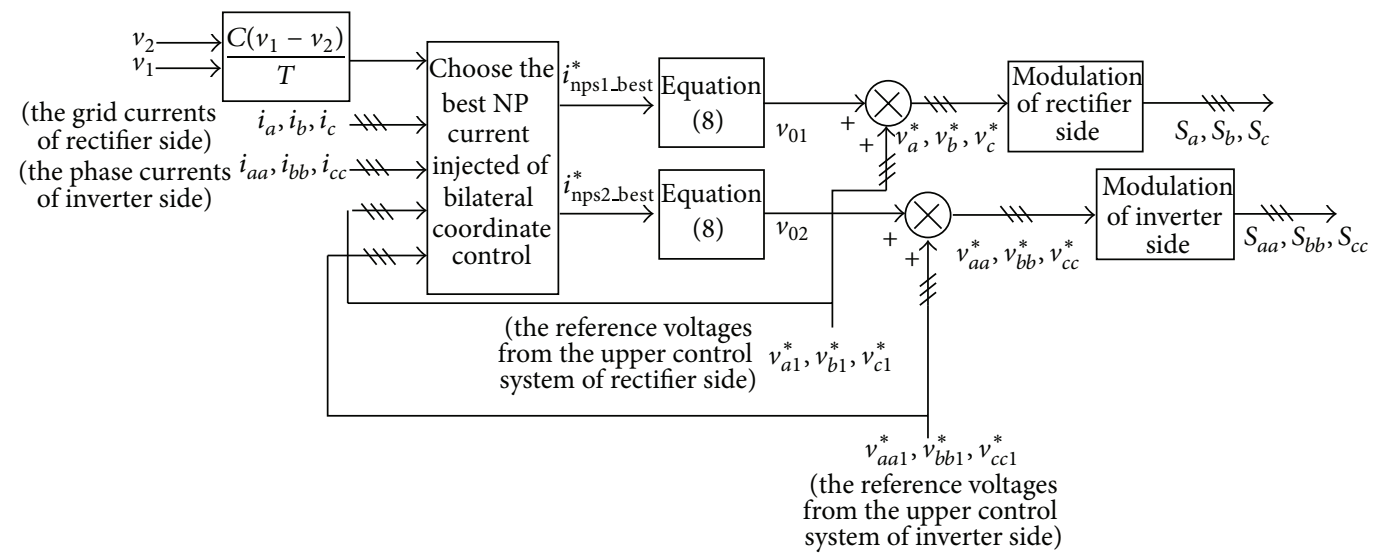

Figure 8: The block diagram of bilateral coordinated control.

two zero-sequence voltages in both sides. Likewise, for line $L_{5}, n\left(i_{m i}, i_{x r}\right)$ is the nearest point. Line $L_{2}$ goes through the shaded area, and the red line represents the overlap. In this case, the NP potential could be balanced as long as the NP currents injected in both sides are taken from the red line. Lines $L_{3}$ and $L_{4}$ have the similar case with line $L_{2}$.

Determine possible case and find the appropriate NP currents injected in both sides to make the NP-potential stable or least fluctuation. Finally, the zero-sequence voltages in both sides are calculated by (8), respectively. The coordinated control flow is shown in Figure 8.

\section{Comparative Analysis of the Three Proposed Algorithms}

Suppose the reference voltages obtained from the upper system and the currents in the both sides all are the ideal positive-sequence waves. The equations are shown in the following:

$$
\begin{gathered}
u_{a 1}^{*}=U \cos (\omega t+\theta), \quad i_{a}=I \cos (\omega t+\tau) \\
u_{b 1}^{*}=U \cos \left(\omega t+\theta-\frac{2 \pi}{3}\right), \quad i_{b}=I \cos \left(\omega t-\frac{2 \pi}{3}+\tau\right) \\
u_{c 1}^{*}=U \cos \left(\omega t+\theta+\frac{2 \pi}{3}\right), \quad i_{c}=I \cos \left(\omega t+\frac{2 \pi}{3}+\tau\right) \\
u_{a a 1}^{*}=U^{\prime} \cos \left(\omega^{\prime} t+\theta^{\prime}\right), \quad i_{a a}=I^{\prime} \cos \left(\omega^{\prime} t+\tau^{\prime}\right) \\
u_{b b 1}^{*}=U^{\prime} \cos \left(\omega^{\prime} t+\theta^{\prime}-\frac{2 \pi}{3}\right), \\
i_{b b}=I^{\prime} \cos \left(\omega^{\prime} t-\frac{2 \pi}{3}+\tau^{\prime}\right) \\
u_{c c 1}^{*}=U^{\prime} \cos \left(\omega^{\prime} t+\theta^{\prime}+\frac{2 \pi}{3}\right), \\
i_{c c}=I^{\prime} \cos \left(\omega^{\prime} t+\frac{2 \pi}{3}+\tau^{\prime}\right) .
\end{gathered}
$$

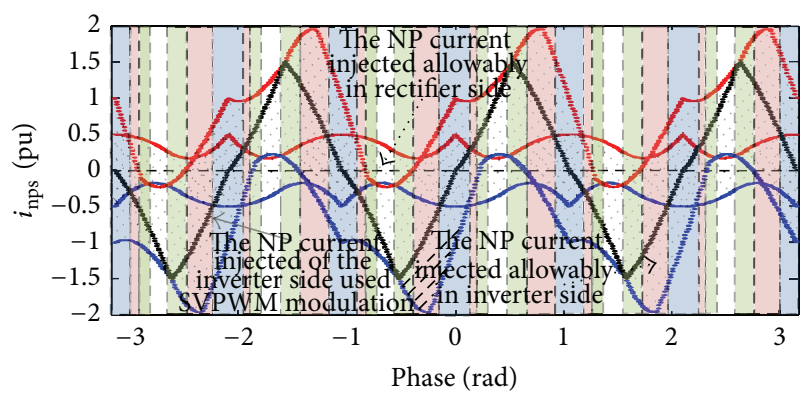

FIGURE 9: The performance of the three proposed algorithms.

In order to analyze the performance of these three proposed algorithms, the relevant parameters are as follows:

$$
\begin{gathered}
m=U=0.8, \quad m^{\prime}=U^{\prime}=1 \\
\varphi=\theta-\tau=0, \quad \varphi^{\prime}=\theta^{\prime}-\tau^{\prime}=\frac{\pi}{3} \\
\omega=\omega^{\prime}=314 \mathrm{rad} / \mathrm{s},
\end{gathered}
$$

where $m, m^{\prime}$ are, respectively, modulation ratios of the rectifier side and the inverter side. $\varphi, \varphi^{\prime}$ are, respectively, power factor angles of the rectifier side and the inverter side.

So the amplitude of the grid current in the rectifier side is twice as large as in the inverter side in accordance with the same active power of both sides:

$$
I=\frac{I^{\prime}}{2}
$$

The basic value of all the currents is the grid-current amplitude. The two NP-current injection ranges in rectifier side and inverter side can be calculated by Table 1. If the two ranges are put together, the performance of the three proposed algorithms could be analyzed, as shown in Figure 9.

Traditional SVPWM modulation is used in the inverter side under unilateral control. Due to the fixed zero-sequence voltage value in traditional SVPWM modulation, the NP 


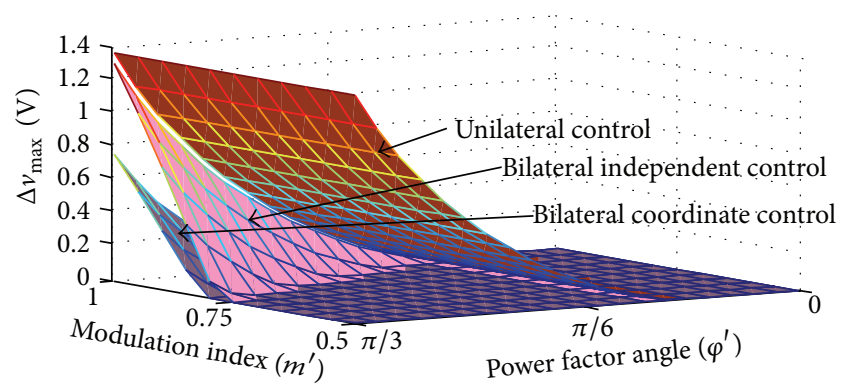

FIgURE 10: The maximum NP-potential fluctuations of the three proposed algorithms.

current injected in the inverter side is known, which is shown by the black line in Figure 9. When the bilateral independent control and bilateral coordination control are used, the two NP-current injection ranges in rectifier side and inverter side are shown by shaded slashes in Figure 9. The NP-current injection range in rectifier side is expressed by the shaded forward slashes. The NP-current injection range in inverter side is expressed by the shaded backslashes. The blue areas show the overlap between the NP-current injection range in rectifier side and the NP current injected in the inverter side with SVPWM modulation. In these areas, unilateral control may not make the NP potential fluctuate. The red areas and the blue areas show that the NP currents injected in both sides may be taken to zero. In these areas, bilateral independent control may not make the NP potential fluctuate. The green areas, red areas, and the blue areas show that the difference of the NP currents injected in both sides may be taken to zero. In these areas, bilateral coordination control may not make the NP potential fluctuate. So bilateral coordination control has the best effect. But in a 2 pi cycle, the NP currents obtained by the above-mentioned algorithms may not be able to fully meet the demand. If the difference between the NP currents injected in both sides are accumulated in each switching cycle, the maximum electric charge flowing in or out the capacitance in a 2 pi cycle can be calculated. So the maximum fluctuation of the NP potential can be given by

$$
\max \left(v_{1}-v_{2}\right)=\Delta v_{\max }=\frac{\Delta Q_{\max }}{C}=\frac{\sum_{k=1}^{n} \Delta i_{k} \cdot T}{C},
$$

where $\Delta i_{k}=i_{\text {nps } 1}(k T)-i_{\text {nps } 2}(k T)$.

When the power factor or modulation ratio of the inverter side is changed, the maximum fluctuations of NP-potential obtained by the three proposed algorithms can be composed of three curved surfaces, as shown in Figure 10. The capacitance value $C$ is set to $1 \mathrm{mF}$ in (16). When the modulation ratio is smaller and the power factor is greater, the NP-potential fluctuation of the three proposed algorithms will be smaller. The NP-potential fluctuation of bilateral coordination control is the smallest.

\section{Simulation Results}

A simulation system of the three-level NPC back-to-back converter is built to verify the three proposed algorithms.

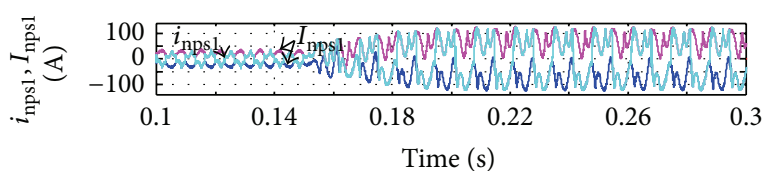

(a)

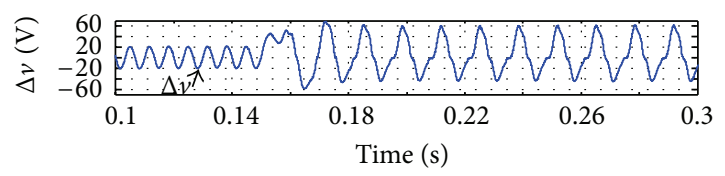

(b)

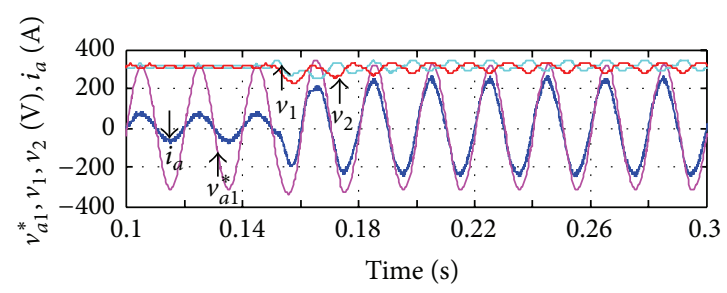

(c)

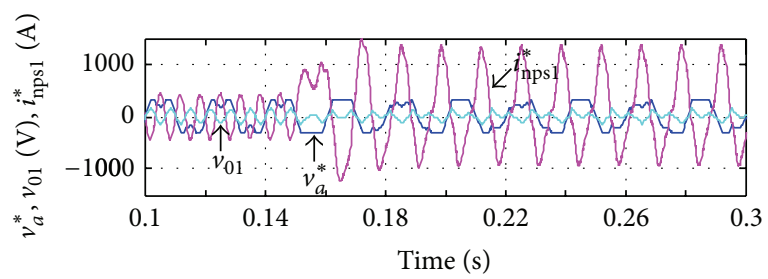

(d)

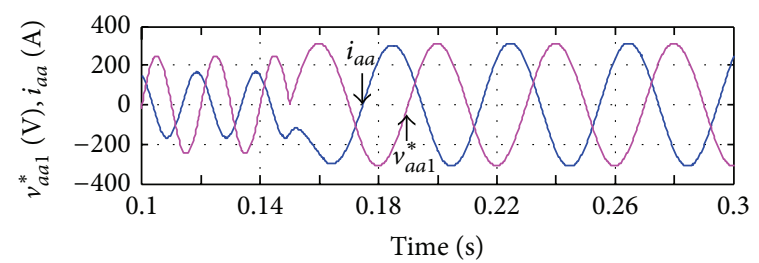

(e)

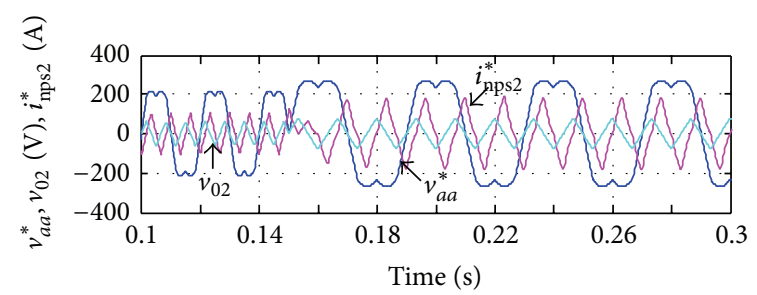

(f)

FIGURE 11: Simulation results of unilateral control.

The parameters are listed as follows: $u_{\mathrm{dc}}=622 \mathrm{~V}, \mathrm{C}=4 \mathrm{mF}$, $f_{\text {sw }}=5 \mathrm{kHz}(T=0.0002 \mathrm{~s}), f_{\text {grid }}=50 \mathrm{~Hz}, E_{\text {grid }}(\mathrm{rms})=220 \mathrm{~V}$, $\omega=314 \mathrm{rad} / \mathrm{s}, R_{\text {load }}=0.75 \Omega$, and $L_{\text {load }}=4.13 \mathrm{mH}$.

Figures 11, 12, and 13, respectively, show the simulation results of unilateral control, bilateral independent control, and bilateral coordinate control in multiple step signals. At $0.15 \mathrm{~s}$, the frequency of the reference voltage in the inverter side $\omega^{\prime}$ mutates from $50 \mathrm{~Hz}$ to $25 \mathrm{~Hz}$, and the modulation ratio $m^{\prime}$ mutates from 0.8 to 1 , and the reference-voltage phase 


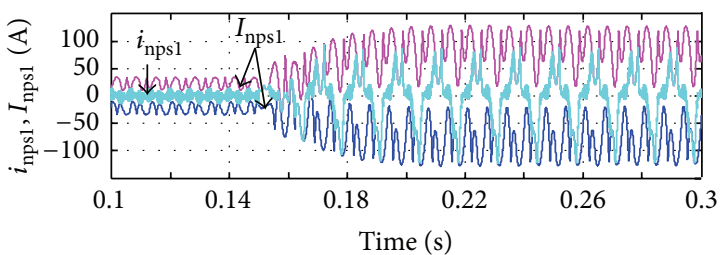

(a)

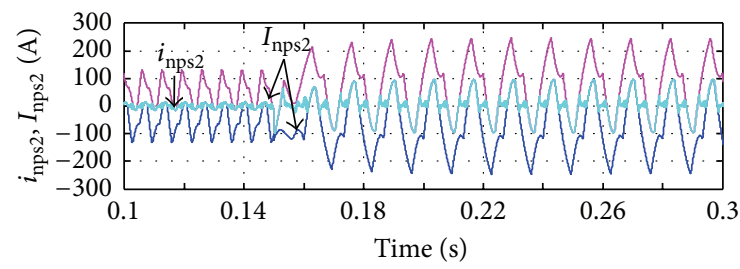

(b)

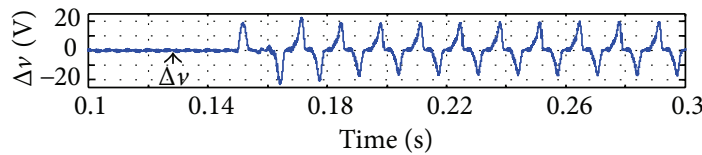

(c)

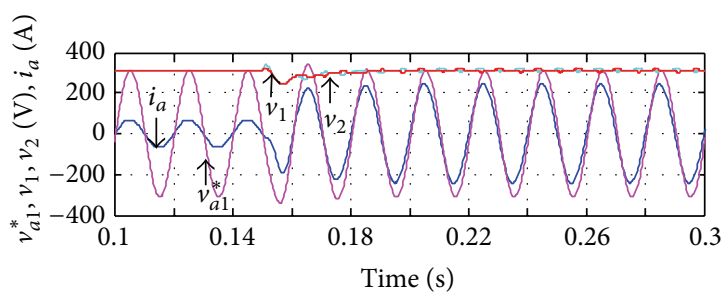

(d)

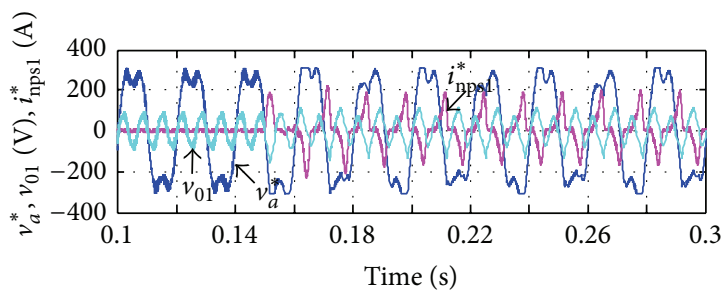

(e)

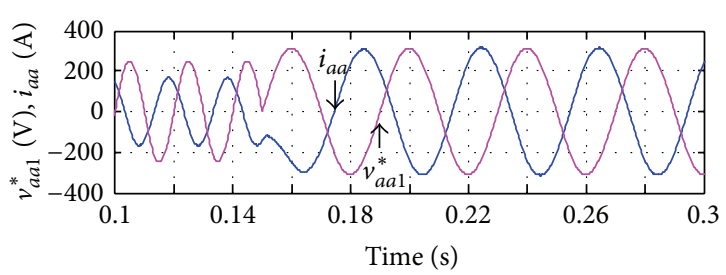

(f)

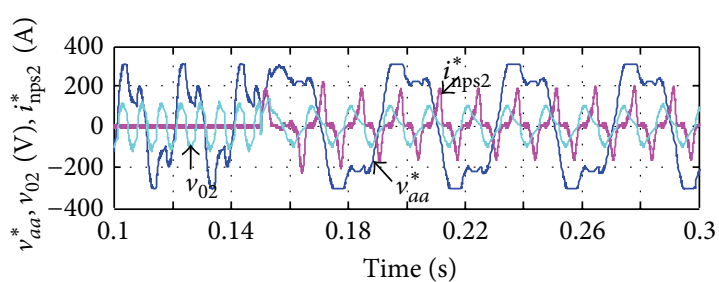

(g)

FIGURE 12: Simulation results of bilateral independent control.

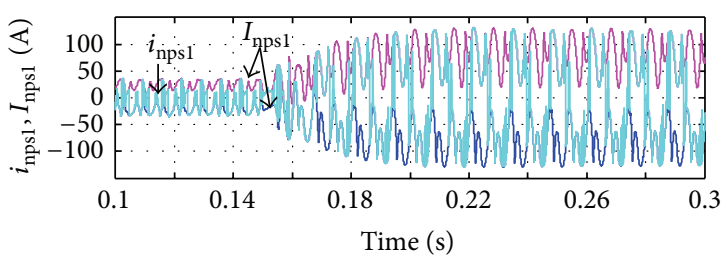

(a)

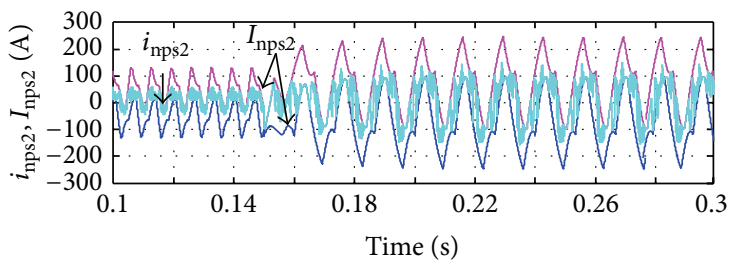

(b)

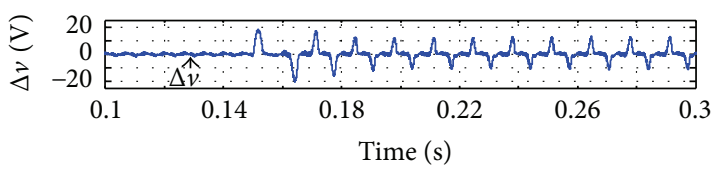

(c)

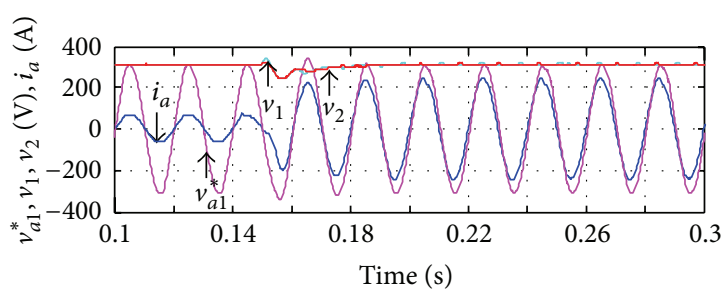

(d)

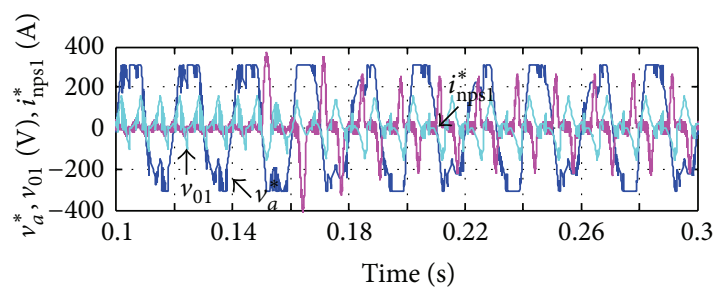

(e)

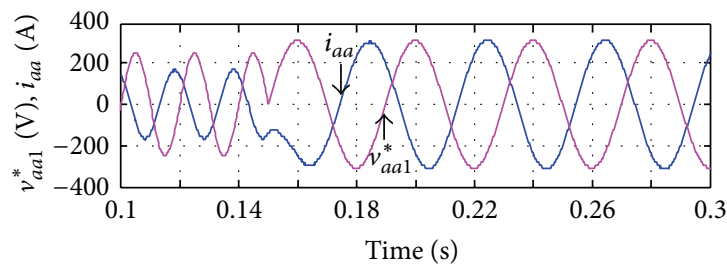

(f)

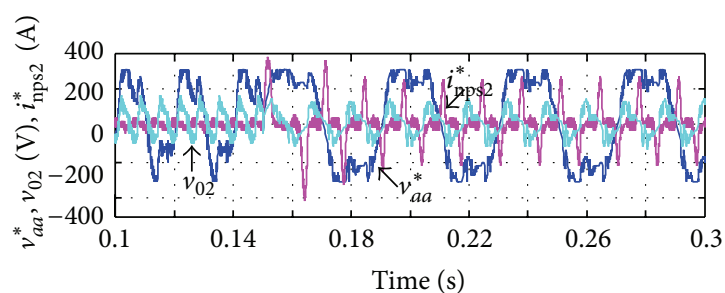

(g)

FIGURE 13: Simulation results of bilateral coordinate control. 

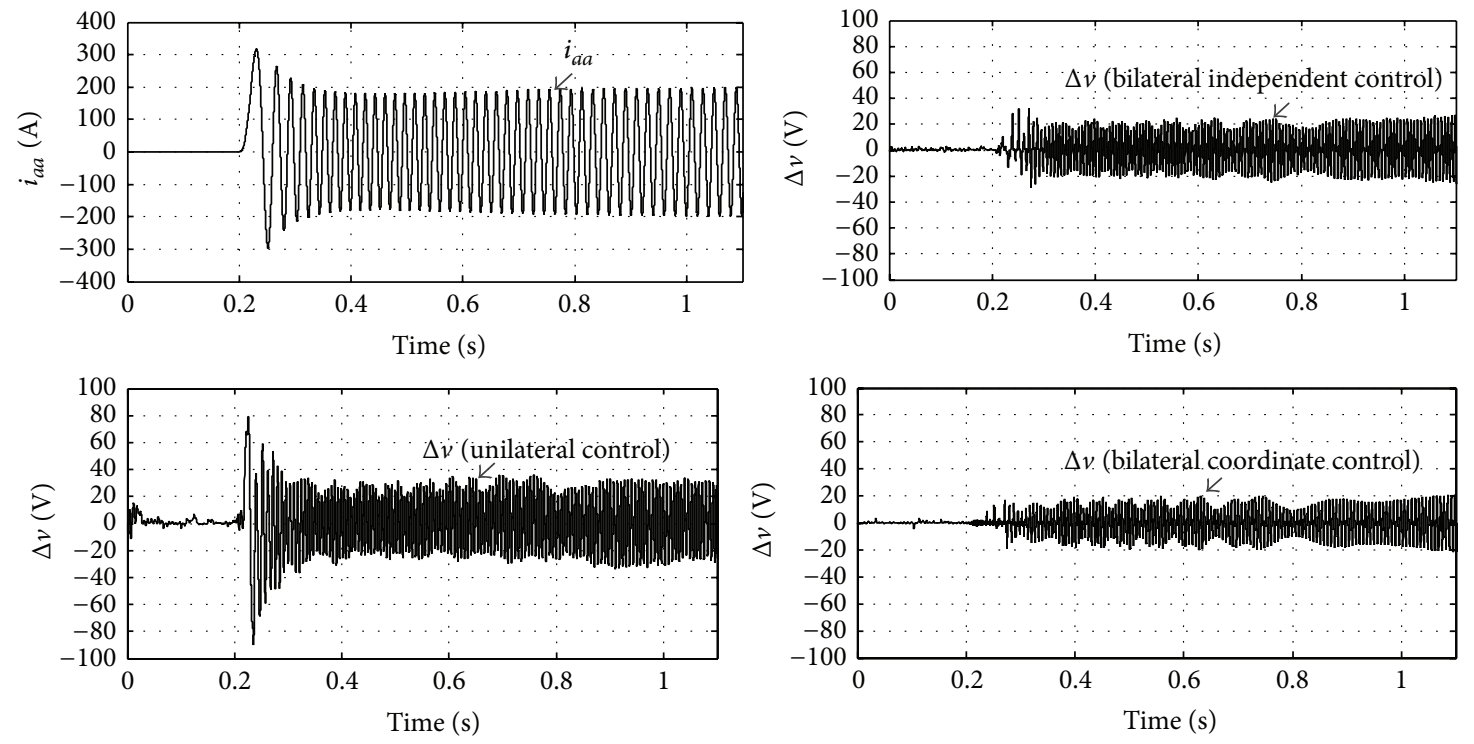

FIGURE 14: Simulation results of the three proposed algorithms ( $\omega^{\prime}$ change: $0 \rightarrow 50 \mathrm{~Hz}$ ).
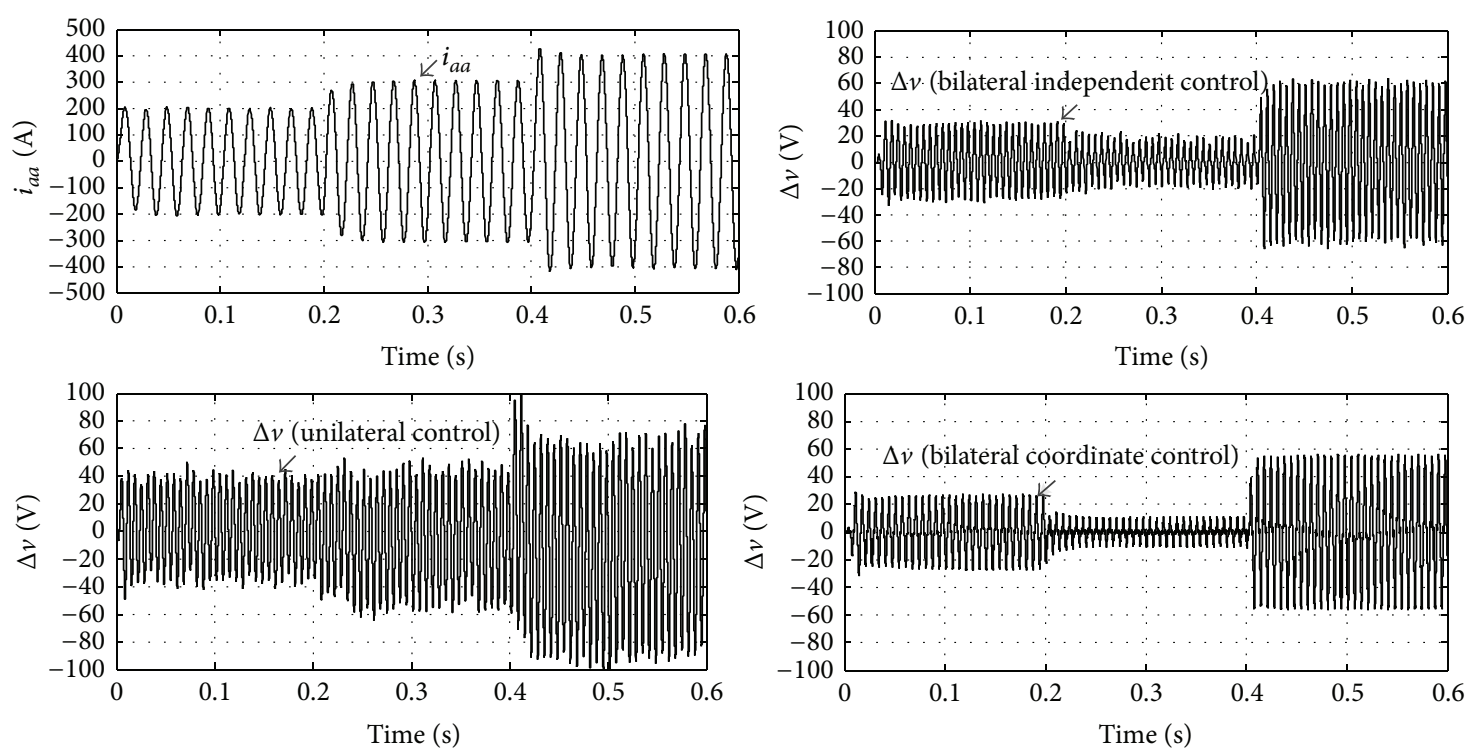

FIGURE 15: Simulation results of the three proposed algorithms (load mutation).

difference between the inverter side and the rectifier side mutates from 0 to $\pi / 2$. $I_{\text {nps } 1}$ and $I_{\text {nps } 2}$, respectively, represent the NP-current injection ranges in rectifier side and inverter side. $v_{01}, v_{02}$, respectively, represent the zero-sequence voltage injected in rectifier side and inverter side.

As shown in Figures 11-13, the NP current injected in rectifier side does not exceed $I_{\text {npsl }}$, and the NP current injected in inverter side does not exceed $I_{\text {nps2 }}$. After injecting the zero-sequence voltage, the voltage amplitude in rectifier side and inverter side is less than or equal to $u_{\mathrm{dc}} / 2=311 \mathrm{~V}$.

Figure 14 shows the performance of these three proposed algorithms when the frequency continuously changes. The fluctuation of the NP potential is held within limits and controlled when $\omega^{\prime}$ continuously changes from $0 \mathrm{~Hz}$ to $50 \mathrm{~Hz}$.
Figure 15 shows the performance of these three proposed algorithms when the power factor and the currents mutate with the loads. $R_{\text {load }}$ mutates from $0.75 \Omega$ to $0.2 \Omega$ at $0.2 \mathrm{~s}$, and $L_{\text {load }}$ mutates from $4.13 \mathrm{mH}$ to $2.13 \mathrm{mH}$ at $0.4 \mathrm{~s}$. After $0.2 \mathrm{~s}$, the impedance decreases and the power factor increases, so the fluctuation of the NP potential by bilateral independent control and bilateral coordinate control decreases. After $0.4 \mathrm{~s}$, the inductance decreases and the power factor almost recovers the original value, but the fluctuation of the NP potential almost increases two times than before $0.2 \mathrm{~s}$ because the current in converter side also grows two times. Figure 16 shows the performance of these three proposed algorithms when modulation ratio mutates with the grid voltages. The grid voltages drop $30 \%$ at $0.2 \mathrm{~s}$ and return to normal at $0.4 \mathrm{~s}$. 

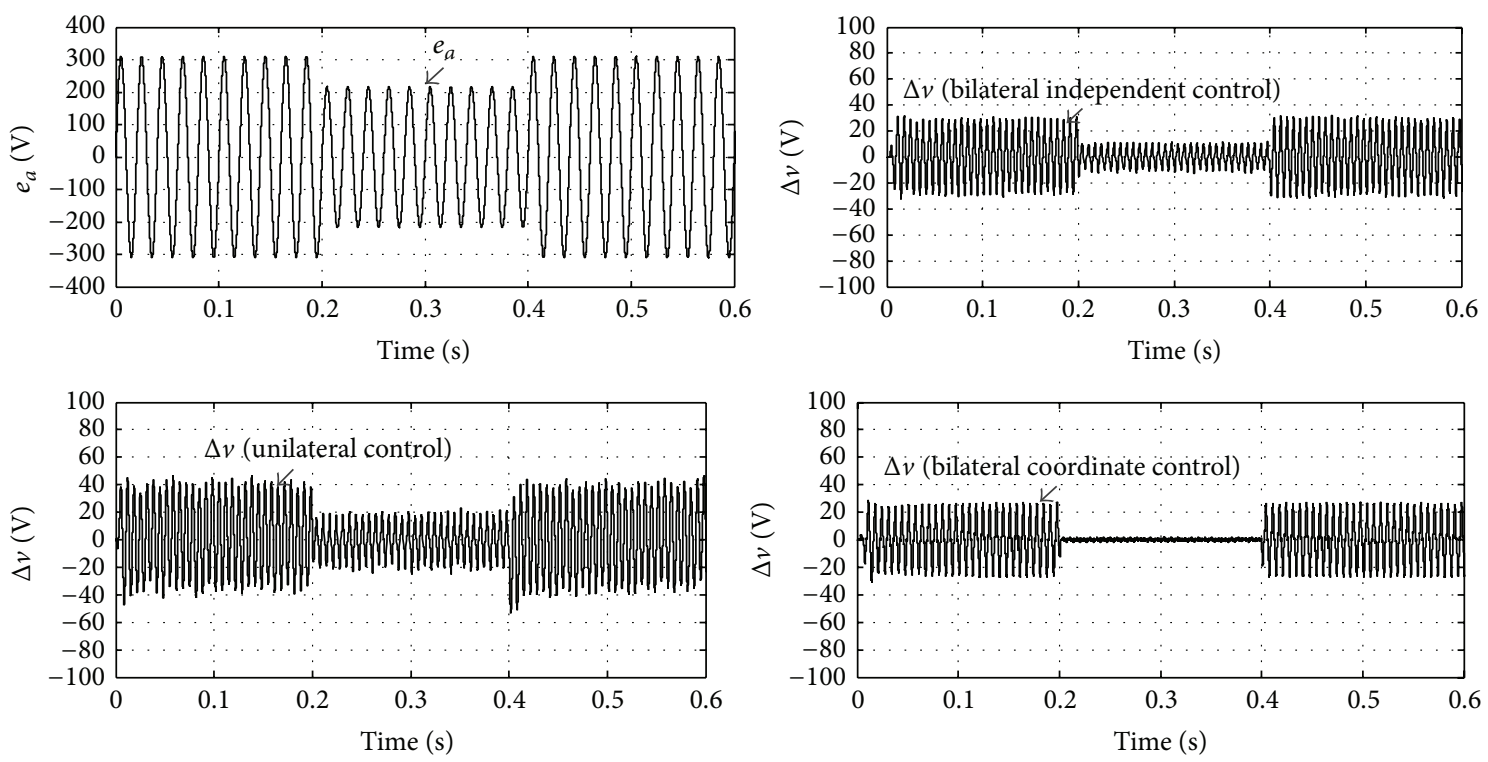

FIGURE 16: Simulation results of the three proposed algorithms (the grid voltages mutation).

The fluctuation of the NP potential falls sharply because the modulation ratio $m$ of rectifier side drops sharply with the grid voltage. $m^{\prime}$ is equal to 0.95 in Figures 14-16.

All these simulation results confirm the effectiveness of the algorithms in a variety of actual situation often encountered. The performance of these algorithms is rowed from high to low in order: bilateral coordination control, bilateral independent control, and unilateral control. Bilateral coordinate control may achieve the minimum of the NPpotential fluctuation.

\section{Conclusion}

The NP potential balancing problem of the three-level NPC back-to-back converter is studied comprehensively in this paper. The proposed NP potential model based on the NP current injected, which can obtain the NP current injected allowably of the single three-level NPC topology, is deduced. And the model can eliminate numerous variable constraints and mutual coupling in the conventional model based on the zero-sequence voltage injected. According to difference requirements, this paper proposes unilateral control, bilateral independent control, and bilateral coordinate control for the three-level NPC back-to-back converter. Comparative analysis shows that unilateral control is simple and conducive to meet some certain specific requirements in the inverter side. In bilateral independent control, zero-sequence voltages of rectifier side and inverter side are independently calculated, which are conducive to modular for the rectifier side and inverter side. Compared with unilateral control, bilateral independent control has a great improvement in the effect of balancing the NP potential. Bilateral coordinate control works best, but both sides need to work together for the zero-sequence voltage calculation. So bilateral coordination control is favorable for some occasions with strict harmonics requirements.

\section{Conflict of Interests}

The authors declare that there is no conflict of interests regarding the publication of this paper.

\section{Acknowledgments}

The authors would like to give thanks for project support by Specialized Research Fund for the Doctoral Program of Higher Education (20120095110017), China Postdoctoral Science Foundation (2014M561726) and National Natural Science Foundation of China (51377160).

\section{References}

[1] Z. Ye, H. Li, W. Jing, and Z. Hou, "Control system of dual three-level double-fed induction motor," Transactions of China Electrotechnical Society, vol. 24, no. 6, pp. 24-29, 2009.

[2] R. K. Behera, S. P. Das, and O. Ojo, "Utility friendly threelevel neutral point clamped converter-fed high-performance induction motor drive," IET Power Electronics, vol. 5, no. 7, pp. 1196-1203, 2012.

[3] L. Lin, Research on induction motor direct torque control system fed by dual three-level converter [Ph.D. thesis], Huazhong University of Science and Technology, Wuhan, China, 2007.

[4] R. C. Portillo, M. M. Prats, J. I. Leon et al., "Modeling strategy for back-to-back three-level converters applied to high-power wind turbines," IEEE Transactions on Industrial Electronics, vol. 53, no. 5, pp. 1483-1491, 2006.

[5] J. Shen, S. Schröder, R. Rösner, and S. El-Barbari, "A comprehensive study of neutral-point self-balancing effect in neutralpoint-clamped three-level inverters," IEEE Transactions on Power Electronics, vol. 26, no. 11, pp. 3084-3095, 2011.

[6] J. Pou, E. Robles, S. Ceballos, J. Zaragoza, A. Arias, and P. Ibañez, "Control of back-to-back-connected neutral-pointclamped converters in wind mill applications," in Proceedings of 
the European Conference on Power Electronics and Applications (EPE '07), Aalborg, Denmark, September 2007.

[7] T. Ghennam and E.-M. Berkouk, "Back-to-back three-level converter controlled by a novel space-vector hysteresis current control for wind conversion systems," Electric Power Systems Research, vol. 80, no. 4, pp. 444-455, 2010.

[8] T. Ghennam, E. M. Berkouk, and B. Fançois, "Three-level inverter controlled by means of vector hysteresis current control. Application to back to back structure," in Proceedings of the IEEE International Symposium on Industrial Electronics, pp. 998-1003, Vigo, Spain, June 2007.

[9] L. Li, D. Czarkowski, Y. Liu, and P. Pillay, "Multilevel space vector PWM technique based on phase-shift harmonic suppression," in Proceedings of the 15th Annual IEEE Applied Power Electronics Conference and Exposition (APEC '00), pp. 535-541, New Orleans, La, USA, February 2000.

[10] Y. Wenxi, L. Zhengyu, Z. Rongxiang, F. Wanmin, and Q. Zhaoming, "Hysteresis-band control based PWM strategy of three-level neutral-point balance," in Proceedings of the 20th Annual IEEE Applied Power Electronics Conference and Exposition (APEC '05), pp. 415-418, Austin, Tex, USA, March 2005.

[11] A. Bendre, G. Venkataramanan, D. Rosene, and V. Srinivasan, "Modeling and design of a neutral-point voltage regulator for a three-level diode-clamped inverter using multiple-carrier modulation," IEEE Transactions on Industrial Electronics, vol. 53, no. 3, pp. 718-726, 2006.

[12] S. Busquets Monge, S. Somavilla, J. Bordonau, and D. Boroyevich, "Capacitor voltage balance for the neutral-point-clamped converter using the virtual space vector concept with optimized spectral performance," IEEE Transactions on Power Electronics, vol. 22, no. 4, pp. 1128-1135, 2007.

[13] S. Ogasawara and H. Akagi, "Analysis of variation of neutral point potential in neutral-point-clamped voltage source PWM inverters," in Proceedings of the Conference Record of Industry Applications Society Annual Meeting, pp. 965-970, Toronto, Canada, October 1993.

[14] Y.-Q. Meng, C.-W. Shen, Z. Liu, X.-L. Ji, and Y.-M. Su, "Study on neutral-point potential control method for three-level NPC rectifiers by injecting zero-sequence voltage," Proceedings of the Chinese Society of Electrical Engineering, vol. 27, no. 10, pp. 9297, 2007.

[15] J. Pou, J. Zaragoza, S. Ceballos, M. Saeedifard, and D. Boroyevich, "A carrier-based PWM strategy with zero-sequence voltage injection for a three-level neutral-point-clamped converter," IEEE Transactions on Power Electronics, vol. 27, no. 2, pp. 642651, 2012.

[16] J. Pou, R. Pindado, D. Boroyevich, and P. Rodríguez, "Limits of the neutral-point balance in back-to-back-connected threelevel converters," IEEE Transactions on Power Electronics, vol. 19, no. 3, pp. 722-731, 2004.

[17] K. Tian, M. Wang, and S. Liu, "A neutral-point potential balancing technique implemented at the front end in backto-back-connected three-level converter," in Proceedings of the 3rd IEEE Conference on Industrial Electronics and Applications (ICIEA '08), pp. 1141-1145, Singapore, June 2008.

[18] A. Hodder, J.-J. Simond, and A. Schwery, “Unbalanced DC-Link voltage regulation in a back-to-back 3-level PWM converter for a double-fed induction motor-generator," IEE ProceedingsElectric Power Applications, vol. 152, no. 6, pp. 1477-1481, 2005. 


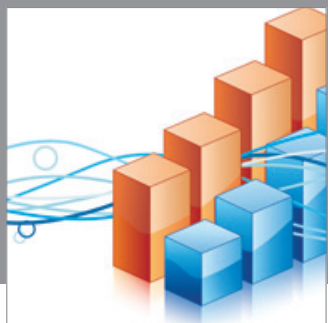

Advances in

Operations Research

mansans

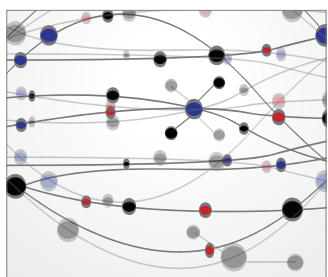

The Scientific World Journal
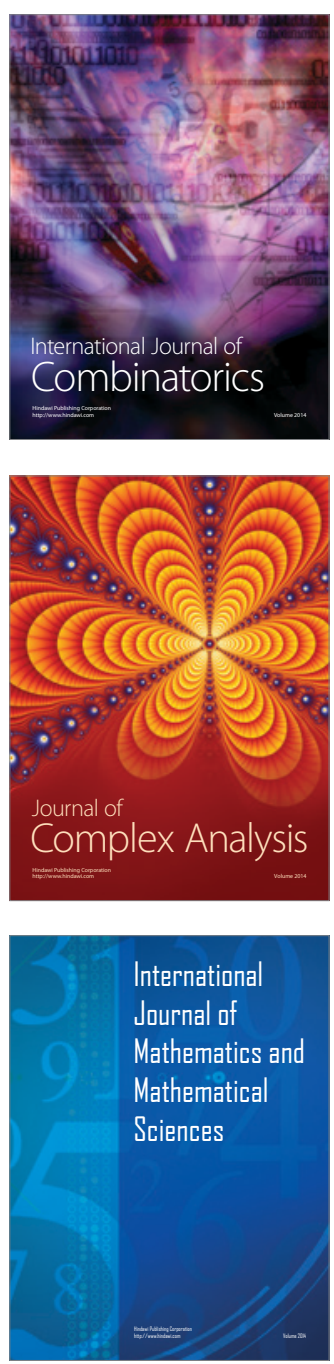
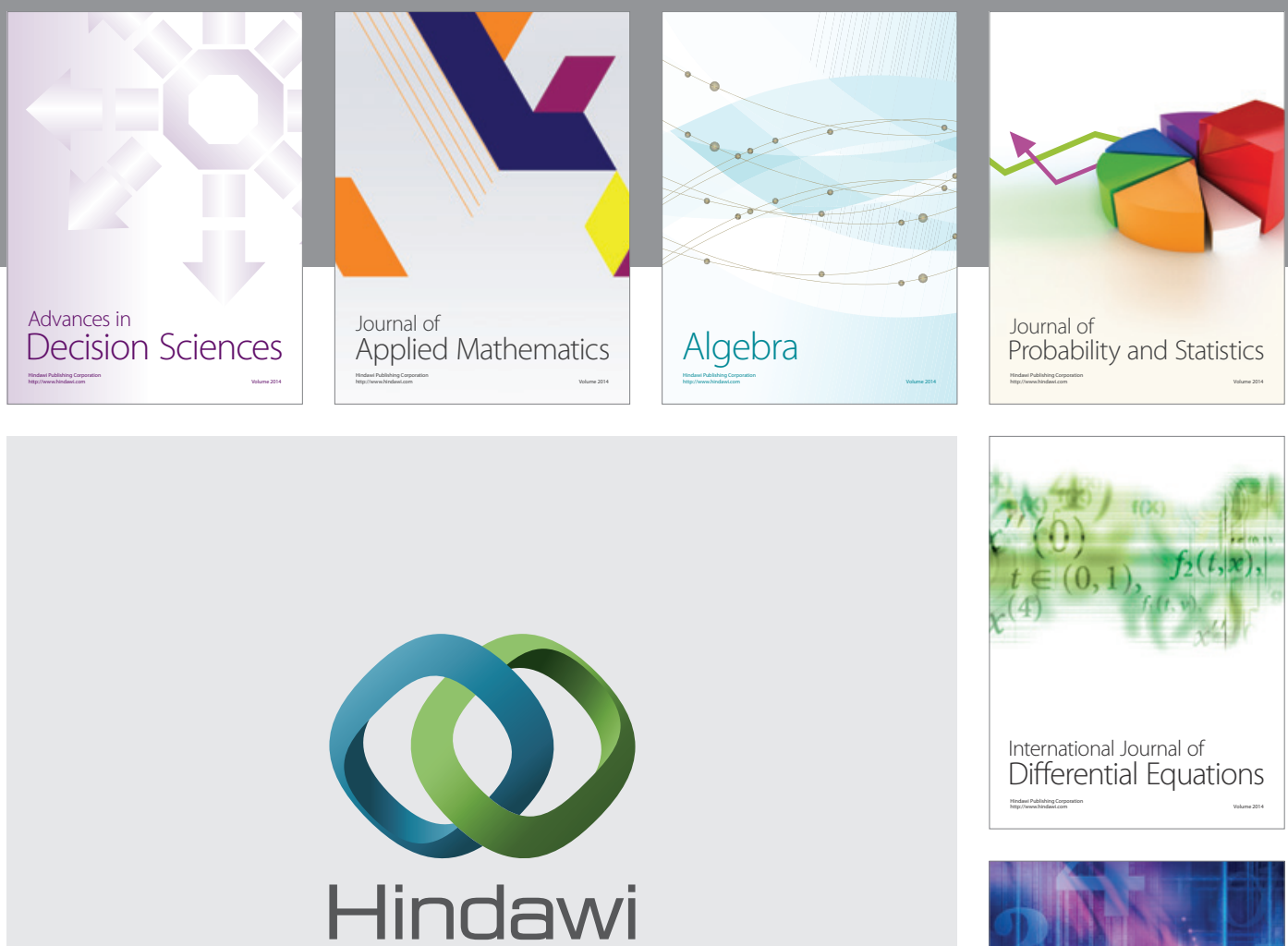

Submit your manuscripts at http://www.hindawi.com
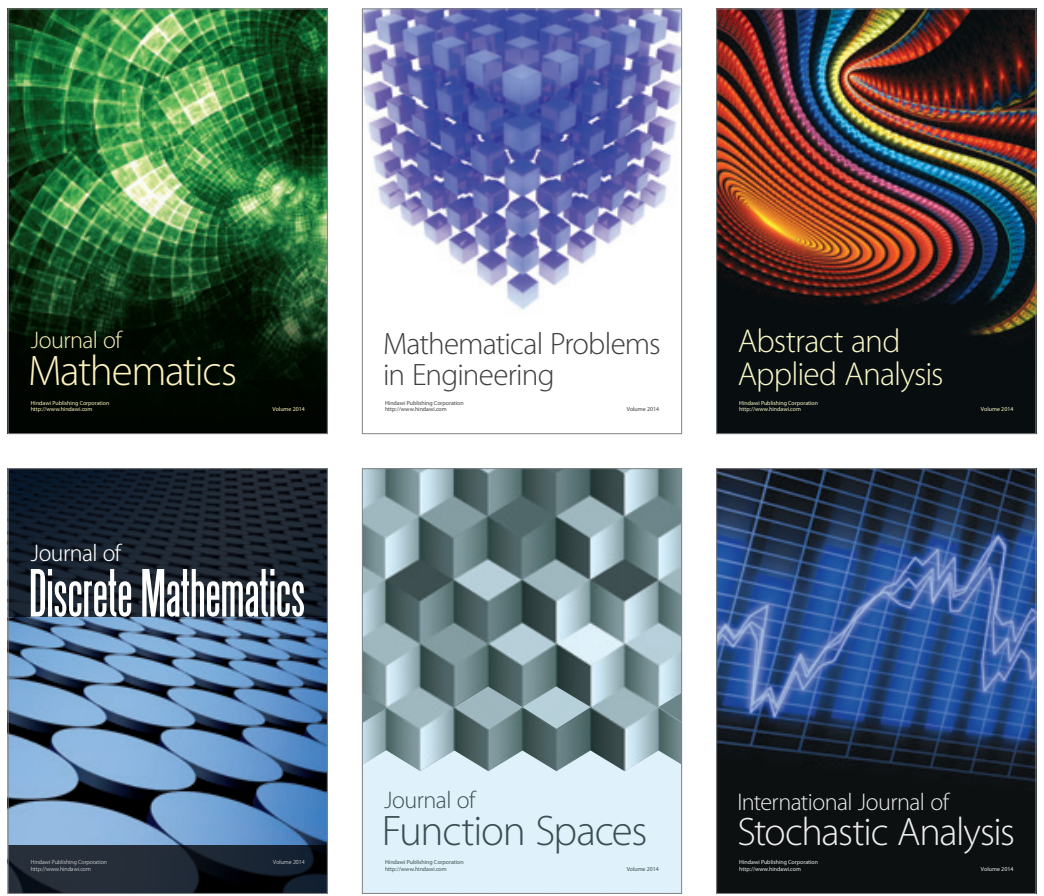

Journal of

Function Spaces

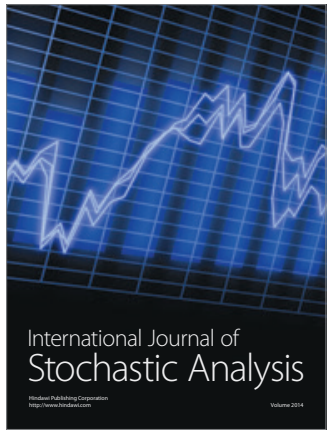

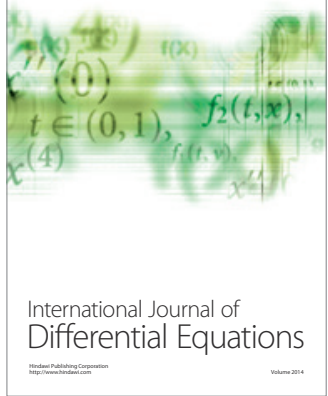
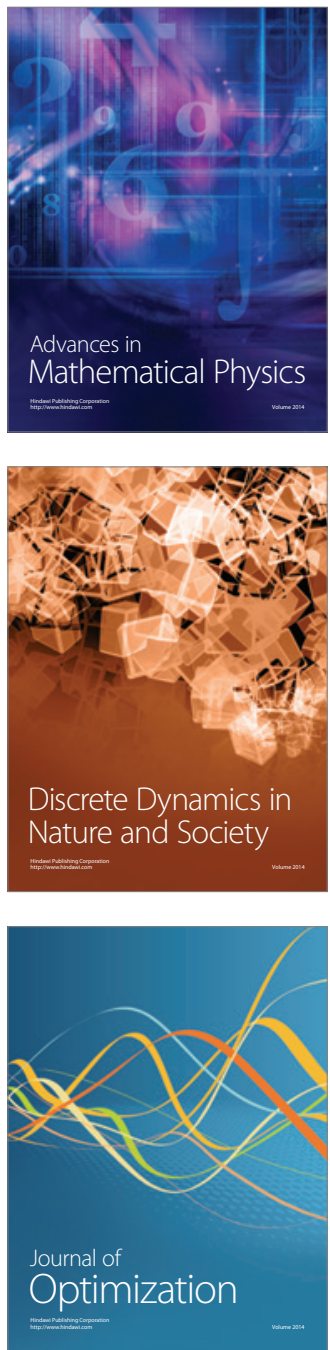